\title{
A model of resource needs of aging spinal cord injured men
}

\author{
M A McColl PhD, ${ }^{1,2} \mathrm{C}$ Rosenthal $\mathrm{PhD}^{3,4}$ \\ ${ }^{1}$ School of Rehabilitation Therapy, Queen's University, Kingston, Ontario, Canada, \\ K7L-3N6; ${ }^{2}$ Lyndhurst Spinal Cord Centre, Toronto, Ontario, Canada; ${ }^{3}$ Department of \\ Occupational Therapy, University of Toronto, Toronto, Ontario, Canada; ${ }^{4}$ Centre for \\ Studies of Aging, University of Toronto, Toronto, Ontario, Canada.
}

\begin{abstract}
It has always been understood that those who deal effectively with a disability call upon special resources that members of the able bodied population are not required to develop. However, the nature and relationship of these resources to aging outcomes is as yet only superficially understood. The present study provides further information and clarification about the resources needed for aging with a spinal cord injury. The sample consists of 70 individuals who have had a spinal cord injury for at least 15 years, and who are currently over the age of 45 , and are therefore either anticipating or experiencing aging. Data from the sample were examined to produce a model of resources empirically associated with positive outcomes in aging. Emotional support was found to be positively related to the outcomes of life satisfaction, adjustment to disability and the absence of depressive symptomatology. Further, health concerns, financial security and instrumental support were also related to specific outcomes. These findings send a clear message to rehabilitation and community service providers to be watchful of survivors with limited social support, concerns about their health and an apparent lack of financial resources. The findings underline the need for better access to health services, and improved knowledge and attitudes of community health care providers working with older disabled individuals.
\end{abstract}

Keywords: spinal cord injury; aging; community health; resources.

\section{Introduction}

It has always been understood that those who deal effectively with life with a disability call upon special resources that members of the able bodied population for the most part are not required to develop. However, just exactly what these resources are is not well understood. A number of authors have speculated about the nature and quality of resources for aging with a disability. In one of the earliest publications to deal comprehensively with this topic, Trieschmann ${ }^{1}$ applies her model of psychosocial, organic and environmental resources to discuss needs associated with aging. Focusing on environmental resources, she notes the need for community resources, particularly attendant care, community support services, equipment, and knowledgeable professionals. In a review of the primary health care needs of people with physical disabilities, Burns and colleagues $^{2}$ also identify the importance of home health care services, delivered by knowledgeable providers, and covered by third-party insurance.

In studies looking at the relationships of various resources to outcomes, however, formal supports are seldom mentioned. A number of recent studies have looked at the resources associated with positive outcomes among aging spinal cord injured individuals. Intuitively, one would assume that important resources would be those abilities that are spared by the injury or illness. In other words, one would expect that the extent of disability would be inversely related to positive outcomes. This idea is supported by research with the aging general population: 
the more disability, the greater the likelihood that the individual will be depressed. . $^{3,4}$ Further, it is supported by research with other disabled populations. ${ }^{5,6}$ However, there is some disagreement among researchers as to its importance among spinal cord injured samples. Cushman \& Haslett $^{7}$ looked at spinal cord injured individuals 10 and 15 years post injury, and found that the level of lesion was not related to quality of life. Siosteen and colleagues ${ }^{8}$ looked at three groups of spinal cord injured adults representing three distinct functional disability levels. They found that quality of life did not differ between groups. Whiteneck and colleagues, ${ }^{9}$ in their large English study of aging spinal cord injured adults, found that the level of the lesion did not successfully predict either life satisfaction or wellbeing. On the other hand, Eisenberg \& Saltz ${ }^{10}$ and Gerhart ${ }^{11}$ found that greater functional losses were related to poorer outcomes.

In the general population, health and income are the two factors most highly correlated with psychological well-being and the ability to retain independence in later life. Neither, however, are discussed in any depth in the studies involving spinal cord injured individuals. While Whiteneck and colleagues $^{9}$ and Krause ${ }^{12}$ discuss in detail the changes in health that accompany aging, and the relationship of age to excess morbidity, there is little discussion about the relationship of health complications to general outcomes like quality of life or psychological well-being. As Whiteneck and group ${ }^{9}$ conclude, the relationship of health to outcomes is an area requiring further study.

There is, however, considerable discussion around the issues of age, time since injury and age at injury. Whiteneck and associates $^{9}$ found that both quality of life and life satisfaction declined as spinal cord injured adults reached the age of 50 , and survived beyond 30 years of their injury. No such relationship was seen for psychological well-being. Eisenberg \& Saltz, ${ }^{10}$ in their review of the literature on quality of life and long term outcomes of spinal cord injury, concluded that life satisfaction does vary with age among disabled adults, with those between 45 and 54 and those with disabilities of durations greater than 20 years expressing the least satisfaction. Krause, ${ }^{12}$ however, found a number of dimensions of quality of life, such as economic satisfaction, marital satisfaction, and overall life satisfaction increased significantly over a 15 year period following the onset of disability. However, the average age of his sample was relatively low, with an average of 45 years at follow up. Notably, the average age of Krause's sample is below the age where Whiteneck's sample began to report declines in these psychological outcomes.

In an effort to disentangle these temporal variables, Krause \& Crewe $^{13}$ studied two samples of spinal cord injured adults, and found that chronological age was negatively related to several areas of life satisfaction, including activity level and self-rated adjustment, especially among those over 55 . Time since injury, on the other hand, was found to be positively related to adjustment and psychological outcomes. Thus age and time since injury seem to work in opposing directions, with those who were injured young, and are still relatively young being in the most favoured position. Taken together, these studies suggest that there is still some room for clarification about the relationship of time to outcomes, and the relationships among outcomes. Of interest are the variety of outcomes researchers have chosen to study, and the relationships of determinants to these different outcomes.

A final resource for aging that has been extensively studied in the general population is informal social support. Marital status, family structure, and the perceived presence of friends and family are all seen as important contributors to an individual's ability to sustain the lifestyle he or she wishes. In particular, Penning ${ }^{14}$ and Grant and colleagues ${ }^{15}$ point to the importance of emotional support for overall satisfaction and adaptive outcomes. Schulz \& Decker, ${ }^{16}$ in their spinal cord injured sample, found that spouses and children were most important in terms of the support provided. This finding is consistent with studies of support in other populations. Brillhart ${ }^{17}$ too noted the importance of social supports for 143 disabled students at colleges and universi- 
ties. In this young sample, she found sources and types of support closely related.

In the present study, we attempt to provide further information and clarification about the resources needed for aging with a spinal cord injury. We have chosen a sample made up of individuals who have had a spinal cord injury for at least 15 years, and who are currently either anticipating or experiencing aging. Thus, according to other studies, ${ }^{9,13}$ the sample may be considered to be at risk of poor adaptive outcomes because of their age. Data from this sample were examined to produce a model of resources empirically associated with positive outcomes. In an effort to clarify the pertinent outcomes associated with aging and disability, three different outcomes (depressive symptomatology, adjustment to disability and life satisfaction) are considered, and the relationships between them examined.

\section{Method}

\section{Sample}

Subjects for the study were recruited from Lyndhurst Spinal Cord Centre in Toronto, Canada, through the Lyndhurst Rehabilitation Database. This database includes records from about 3,000 spinal cord injured adults rehabilitated at Lyndhurst since January 1945 . Subjects were included if they were male, had had a spinal cord injury at least 15 years ago, were 45 years of age or older, lived in the Toronto area, and could be traced to an address where they could be contacted. The sample was restricted to males for two reasons. In the spinal cord injured population, it is difficult to generate a large sample of aging females, because of the history and distribution of the disability; specifically, because about $80 \%$ of spinal cord injuries affect men. Further, the issues of aging disabled women are notably different from those of aging disabled men, due to differences in marital status, financial security and the availability of others to provide care. In recognition of the unique nature of women's issues, it was determined that they would be studied separately at a later date. Subjects were excluded from the study if they were not mentally competent to under- go the interview or were not able to carry out the interview in English.

Initially, 398 individuals were identified who met the first three inclusion criteria (males, over 45, with injuries for longer than 15 years). Of the initial 398, 257 were excluded because they were either deceased (68); living outside the Metro Toronto area (170); or unable to be interviewed because of language or illness (19). This left 141 eligible subjects, of whom we were unable to locate 63 . Of the remaining 78 , eight refused to participate, leaving 70 subjects who completed the interviews. Characteristics of the sample are presented in Table I.

\section{Measurement}

All data were collected during face-to-face interviews in the participants' homes. The study was designed to test a conceptual model of the resources needed for successful aging with a spinal cord injury. The model

Table I Characteristics of the sample

\begin{tabular}{lccr}
\hline Variable & Value & Frequency & $\%$ \\
\hline Age & $<50$ & 24 & 33.3 \\
& $50-55$ & 11 & 16.7 \\
& $56-60$ & 17 & 25.8 \\
& $61-65$ & 6 & 9.0 \\
& $66-70$ & 8 & 12.2 \\
Marital & $>70$ & 2 & 3.0 \\
status & Married & 38 & 54.3 \\
& Single & 15 & 21.4 \\
Level of & Sep/wid/div & 17 & 24.3 \\
lesion & Cervical & 37 & 52.9 \\
& Thoracic & 27 & 38.5 \\
Age at & Lumbar & 6 & 8.6 \\
injury & $<20$ & 17 & 25.4 \\
& $20-25$ & 24 & 35.8 \\
& $26-30$ & 13 & 19.4 \\
& $31-40$ & 9 & 13.4 \\
& $>40$ & 4 & 6.0 \\
Years since & (missing) & $(3)$ & \\
injury & $15-20$ & 9 & 13.6 \\
& $21-25$ & 11 & 16.7 \\
& $26-30$ & 19 & 28.8 \\
& $31-35$ & 8 & 12.1 \\
& $36-40$ & 9 & 13.6 \\
& $>40$ & 10 & 15.2 \\
& (missing) & $(4)$ & \\
\hline & & &
\end{tabular}


was derived from the literature on aging in both the general population and various disabled populations. Successful aging was operationalized in three ways: life satisfaction, adjustment to disability, and (lack of) depressive symptomatology. The model includes several categories of resources on the determinants side, including sociodemographic factors, injury-related factors, health and support resources. Data for the study were coded, entered and cleaned, using SPSS-PC. Calculation of scale scores and other data reduction procedures also took place using SPSS-PC. Confirmation of measurement properties was conducted, as reported earlier. In this way, the dimensionality and internal consistency of subscale scores were confirmed before proceeding to use the variables in further analysis. Each of the factors in the model was measured as follows.

\section{Outcomes}

The overall outcome of interest was the ability of aging spinal cord injured individuals to have a happy and productive life in the community. This outcome was operationalized in three ways: depressive symptomatology, life satisfaction and adjustment to disability.

Depressive symptomatology was measured using the Centre for Epidemiological Studies Depression scale (CES-D), ${ }^{18}$ a 20 item self report measure used widely to detect depressive symptomatology in nonpsychiatric populations. Recent experience with this measure in the spinal cord injured population showed that the measure was unidimensional and internally consistent (alpha $=0.91) .{ }^{19}$ Work by other authors supports the validity of the CES-D for use with a disabled population. ${ }^{20,21}$

Life satisfaction was measured using a 12 -item index of life satisfaction by Michalos. ${ }^{22,23}$ Items tap satisfaction with health, finances, family relations, employment, friendships, housing, living situation, recreation, religion, self esteem, transportation and life in general. The measure is widely used, and has good reliability and validity.
In the present study, a unidimensional structure is supported, where the first factor explains $40 \%$ of the variance in the measured items, and internal consistency reliability is 0.79 .

Adjustment to disability was measured using the psychosocial dimension of the Sickness Impact Profile, ${ }^{24}$ as adapted by McColl \& Skinner. ${ }^{19}$ The SIP assesses the prevalence of maladaptive behaviours that result from the illness or disability. Reliability and validity of the SIP have been supported by a number of authors. ${ }^{25-28}$ The adapted version of the SIP used in the present study has a one-factor structure which explains $31 \%$ of the variance in the scale, with internal consistency of $0.77 .^{19}$

\section{Determinants}

Demographic factors. Age, marital status and employment were assessed with single items. Financial security was assessed using a measure of income adequacy developed by Feather. ${ }^{29}$

Injury-related factors. Time since injury, age at injury, year of injury, and level of lesion were all assessed with single items. Functional independence was measured using the Functional Independence Measure. ${ }^{30}$ In the present study, the FIM resulted in a unidimensional scale, which explained $79 \%$ of the variance in measured items. The internal consistency of the FIM in this sample was 0.97 .

Health. Self-rated health was assessed using a single item which asks subjects to rate their own health on a seven-point Likert scale. Health concerns and recent illnesses, injuries and surgeries were also assessed with single items. Utilization of health services was assessed using a checklist of nine questions, adapted from a survey of health service utilization by elderly persons. ${ }^{31}$ Additional items pertinent to the service needs of spinal cord injured persons were added (e.g. equipment supplier). A symptom checklist was also adapted ${ }^{31}$ as a third measure of health, which offered respondents choices of 12 acute and chronic 
illnesses, as well as an additional set of five health problems peculiar to spinal cord injured individuals, such as pressure sores, bladder infection or muscle spasms.

Social support. An adaptation of the Interpersonal Support Evaluation List (ISEL) $)^{32,33}$ was used to assess social support. The adapted ISEL asks individuals about the perceived availability of someone to provide specific support functions in each of the areas of instrumental support, emotional support and informational support. Subsequent measurement development with the spinal cord injured population ${ }^{33}$ has resulted in a 25 -item, three-subscale version, based on empirical evaluations with a province-wide sample of 223 spinal cord injured adults. The revised scale has been shown to conform to a factor structure consistent with the theoretical basis for the instrument. For the present application, measurement studies confirmed that the three subscales were in fact unidimensional, with internal consistencies in the acceptance range in all cases (informational 0.90; instrumental 0.95; emotional 0.96).

\section{Results}

\section{Descriptive analysis}

Descriptive analyses, including frequencies, measures of central tendency and distribution, and measures of association, describe the current status of the sample, and the general availability of resources for aging.

With regard to the three outcomes, depressive symptomatology scores were high for the sample. Using the usual cutoff of 16 or greater as a positive indicator of depression on the CES-D, $40 \%$ of the sample screened positive for depression. These values compare extremely poorly with general population estimates, which tend to be below $10 \%$, but also with other work on the spinal cord injured population, where depression has been found to be prevalent in about $28 \%$ of the population. ${ }^{19}$

The Sickness Impact Profile measures adjustment to disability as the number of maladaptive behaviours to which the subject responds positively. Therefore, the higher the SIP score, the greater the number of maladaptive behaviours exhibited. Out of a total of 16 items, the average score was only 2 , with $30 \%$ of subjects reporting none of the maladaptive behaviours. Given the duration of disability experienced by the sample $($ mean $=31.3$ years, $\mathrm{SD}=9.3$, minimum $=16.0$, maximum $=53.3$ ), it may not be surprising that individuals are relatively well adjusted.

Life satisfaction scores out of 84 , made up of 12 seven-point Likert scales, were converted to percents for ease of interpretation. The average score for the sample was $70.2 \%$ $( \pm 16.3)$, with only $8 \%$ of individuals reporting scores below the $50 \%$ mark on the scale, suggesting that the sample members are relatively content with the lives they have carved out for themselves since their injury.

Table II shows the relationships between the three outcomes of interest. Whereas for the SIP and the CES-D, high scores represent greater distress or symptomatology, for life satisfaction, high scores reflect high satisfaction. Thus the expected relationships were seen between these three scales: a positive relationship between depressive symptomatology and maladjustment, and a negative relationship between life satisfaction and both depressive symptomatology and maladjustment. Correlations were significant in all instances.

On the determinants side of the model, $38 \%$ of the sample were employed either full time $(34 \%)$ or part time $(4 \%)$. Twentyone percent reported that they were unemployed and $40 \%$ were retired. This finding must be evaluated relative to the average age of the sample (55.8 years, \pm 8.3 ), as it suggests a tendency towards early retirement. In fact when the retired portion of the sample are examined, their average age was $61.3( \pm 7.6)$, with a range between 46 and 73. Sixty-seven percent of those who were retired were 65 years of age or less.

Financial security, as assessed using the Feather ${ }^{29}$ scale, produced scores between 7 and 49 on seven seven-point Likert scales. The average score was $40.1( \pm 10.9)$, suggesting that these aging disabled individuals generally considered themselves relatively well off. Unfortunately, we do not have information on actual salaries/pensions or 
Table II Relationships between outcome variables

\begin{tabular}{lccc}
\hline & Depression & Life satisfaction & Maladjustment \\
\hline Depression & 1.000 & $-0.710^{\mathrm{a}}$ & $0.699^{\mathrm{a}}$ \\
Life satisfaction & & 1.000 & $-0.506^{\mathrm{a}}$ \\
Maladjustment & & & 1.000 \\
\hline
\end{tabular}

${ }^{\mathrm{a}} p<0.05$.

household incomes, but anecdotal information from the interviews confirms this observation. There were, however, about $12 \%$ of the sample with scores below 25 , which would indicate that they could have reported below the midpoint (3.5) of each of the seven Likert scales.

Injury-related factors used to describe the sample are shown in Table I. In addition, functional status was measured using the FIM, and scores were converted to percents for the purposes of interpretation and comparison with other studies. Twenty-four (34.8\%) participants reported FIM scores lower than the usual cutoff score of 80 for functional independence. In fact, the mean FIM score for the sample is below this standard $(75.7 \pm 25.7)$, but as the standard deviation suggests, there is considerable variation among the scores. About $10 \%$ of the sample appear, according to this measure, to be extremely disabled (i.e. FIM scores $<30$ ). These values may have unduly influenced the mean, as the median for the sample is $90 \%$.

With regard to health, overall perceived health, as assessed with a single seven-point Likert scale, had an average of $5.0( \pm 1.3)$, with $12.9 \%$ of the sample reporting scores below the midpoint of the scale. When asked if they were worried about their health, $13 \%$ stated that they were extremely worried, $27.5 \%$ were very worried, $29 \%$ were somewhat worried and $30 \%$ were not worried. Major illnesses/injuries/surgeries in the past 6 months were reported by 22 , or $31 \%$, of the sample. Further, $12(17 \%)$ reported that they had experienced an illness in the past 2 weeks.

When asked about actual illnesses and symptoms, participants reported that they currently experienced the following: arthritis $(48.5 \%)$; bladder infection $(34.2 \%)$; stomach troubles $(28.6 \%)$; pressure sore $(25.7 \%)$; kidney stones or infection $(18.5 \%)$; chronic fatigue (18.5\%); bowel problems $(17.1 \%)$; respiratory problems $(17.1 \%)$; heart disease $(14.2 \%)$; headaches $(14.2 \%)$. Other complications, such as chest pains, diabetes, cancer, stroke, each accounted for fewer than 10 individuals in the sample. The average number of health problems reported by sample members was $2.8( \pm 2.3)$, with only nine $(13 \%)$ reporting no secondary heath complications.

Utilization of health services was also assessed as a measure of health. Participants were asked about use of six types of doctors in the past 6 months (GP, urologist, physiatrist, chiropractor, dentist, or other doctor). Subjects reported consulting an average of $2.2( \pm 1.2)$ doctors. Individuals were also asked about six types of therapist (psychologist, optometrist, OT/PT, dietician, audiologist, other counsellor). Seventyseven percent (53) of the sample reported seeing no therapist in the past 6 months (average $=0.26 \pm 0.5$ ). Finally, participants were asked about their use of six community services (attendant care, community health nurse, homemaker, meals-on-wheels, equipment supplier, massage therapist). Again, utilization was low, with 54\% not using these services at all (average $=0.88 \pm 1.2$ ).

Finally, social support scores for each of the three subscales (instrumental, informational and emotional support) were converted to percents for comparison and ease of interpretation. For the three types of support, scores were as follows: instrumental 75.1 ( \pm 28.7); informational 53.9 $( \pm 27.2)$; emotional $68.5( \pm 26.0)$. These values are low relative to other uses of this instrument in samples with spinal cord injuries and strokes. ${ }^{19,34}$ 


\section{Multivariate models}

To assess the relative importance of these resources as determinants of outcomes for the sample, multiple regression analyses were undertaken. In the present study, three equations were evaluated, one for each of the three dependent variables: depressive symptomatology, life satisfaction and adjustment to disability. Because the three outcomes were viewed as related but discrete ${ }^{19}$ separate analyses were conducted for each. A backwards stepwise approach was used, with the criterion of $(p>0.10)$ to drop a parameter. In all instances, the most parsimonious solution is reported. Determinants for each equation were chosen from the variables listed earlier, on the basis of theoretical and empirical rationale for their inclusion. Table III shows the bivariate relationships found between determinants and outcomes in preliminary analysis. Table IV shows the results of the multiple regression analyses. Determinants not reported in Table IV were not significant $(p>0.10)$.

For all three equations, emotional social support was a significant predictor of outcomes (depressive symptomatology, life satisfaction and adjustment to disability).
For depressive symptomatology, the presence of health complications was also a significant predictor. As noted above, the sample reported an average of almost three health complications in addition to their spinal cord injury. The more complications an individual reported, the greater the likelihood that he would be depressed.

Life satisfaction was related to three variables, including emotional support, financial security and overall perceived health. In all three instances, the relationship was positive. That is, those with more emotional support, greater financial security and a better perceived health reported greater life satisfaction.

Adjustment to disability was also related to three variables: emotional support, concerns about health and practical support. Those who were most well adjusted to their disability had higher emotional support, lower instrumental support and fewer concerns about their health.

\section{Discussion and conclusions}

To summarize, the findings show that the outcomes of depressive symptomatology,

Table III Significant bivariate correlations with outcomes

\begin{tabular}{|c|c|c|c|}
\hline & Depression & Life satisfaction & Maladjustment \\
\hline \multicolumn{4}{|l|}{ Demographics } \\
\hline \multicolumn{4}{|l|}{ Age } \\
\hline \multicolumn{4}{|l|}{ Marital status } \\
\hline Employment & & $0.290^{\mathrm{a}}$ & \\
\hline Financial security & $-0.355^{b}$ & $0.639^{b}$ & $-0.294^{\mathrm{a}}$ \\
\hline \multicolumn{4}{|l|}{ Injury-related } \\
\hline Time since injury & & $0.305^{\mathrm{a}}$ & \\
\hline Age at injury & & $-0.318^{\mathrm{a}}$ & \\
\hline \multicolumn{4}{|l|}{ Year of injury } \\
\hline \multicolumn{4}{|l|}{ Level of lesion } \\
\hline \multicolumn{4}{|l|}{ FIM score } \\
\hline \multicolumn{4}{|l|}{ Health } \\
\hline Self-assessed & & $0.403^{b}$ & $-0.322^{b}$ \\
\hline Health concerns & $0.356^{\mathrm{b}}$ & $-0.416^{b}$ & $0.485^{\mathrm{b}}$ \\
\hline Utilization & & & \\
\hline Symptoms & $0.343^{\mathrm{b}}$ & & $0.316^{\mathrm{b}}$ \\
\hline \multicolumn{4}{|l|}{ Social support } \\
\hline Instrumental & $-0.515^{b}$ & $0.720^{\mathrm{b}}$ & $0.416^{\mathrm{b}}$ \\
\hline Informational & $-0.548^{b}$ & $0.660^{\mathrm{b}}$ & \\
\hline Emotional & $-0.625^{b}$ & $0.746^{\mathrm{b}}$ & $-0.380^{\mathrm{b}}$ \\
\hline
\end{tabular}

${ }^{\mathrm{a}} p<0.05 ;{ }^{\mathrm{b}} p<0.01$. 
Table IV Results of multiple regression analyses

\begin{tabular}{|c|c|c|c|c|}
\hline Dependent variable & $\begin{array}{c}\mathrm{F}(\mathrm{df}) \\
p\end{array}$ & $\mathrm{R}^{2}$ & Independent variables & $\begin{array}{l}t \\
p\end{array}$ \\
\hline \multirow[t]{2}{*}{ Depression } & $\begin{array}{c}29.84 \\
0.000\end{array}(2,61)$ & 0.478 & Emotional support & $-6.78^{b}$ \\
\hline & & & Health concerns & $3.54^{\mathrm{b}}$ \\
\hline \multirow[t]{2}{*}{ Life satisfaction } & $\begin{array}{c}70.81 \\
0.000\end{array}$ & 0.778 & Emotional support & $7.42^{\mathrm{b}}$ \\
\hline & & & $\begin{array}{l}\text { Self-assessed health } \\
\text { Financial security }\end{array}$ & $\begin{array}{l}5.55^{\mathrm{b}} \\
4.96^{\mathrm{b}}\end{array}$ \\
\hline \multirow[t]{2}{*}{ Maladjustment to disability } & $\begin{array}{c}11.02 \\
0.000\end{array}(3,61)$ & 0.319 & Health concerns & $3.86^{\mathrm{b}}$ \\
\hline & & & $\begin{array}{l}\text { Emotional support } \\
\text { Instrumental support }\end{array}$ & $\begin{array}{r}2.96^{\mathrm{b}} \\
-1.78^{\mathrm{a}}\end{array}$ \\
\hline
\end{tabular}

${ }^{\mathrm{a}} p<0.05 ;{ }^{\mathrm{b}} p<0.01$.

maladjustment and decreased life satisfaction are significantly related to each other, but distinct in terms of their relationships with other variables. Further they show that emotional support is the most consistent predictor of all three outcomes, followed by different combinations of health and economic variables.

The three outcomes of interest (life satisfaction, depressive symptomatology and adjustment to disability), although related to one another, seem to tap different dimensions of outcome, as demonstrated by their differential associations with other variables. The three outcomes studied were chosen for their obvious long term importance, as well as because they had been used in other studies of a similar nature. While all three outcomes were found to be related to emotional support and health variables, life satisfaction was clearly influenced by financial security, and adjustment to disability was negatively affected by instrumental support.

In addition, although the multivariate analyses did not include any demographic or disability-related variables, our bivariate findings substantiate the relationships seen by other authors between outcomes and age, age at onset and duration of disability. The present study found life satisfaction related only to age at onset and duration of disability. ${ }^{9,10,12,13}$ Although these relationships did not persist in the multivariate analysis, financial security was found to be a significant predictor of life satisfaction in the multivariate analysis. One might argue that financial security might be strongly associated with age and time since injury, and might therefore act as a proxy for age and duration.

With regard to the second outcome variable, depressive symptomatology, our findings are consistent with those of other authors, ${ }^{8,9}$ who have found age, duration and severity of disability unrelated to outcome. However, as regards our third outcome, adjustment to disability, we were unable to find evidence to substantiate the relationships seen by Krause \& Crewe ${ }^{12,13}$ with age and duration of disability. This may be because of the older age and the minimum 15 year duration of our sample. Because of these two criteria, adjustment may have plateaued in our sample, and may therefore not show significant relationships with age and duration beyond a certain point. This interpretation is supported by the moderate variance seen in the adjustment variable.

These findings allow us to reflect briefly on the nature of the three variables considered. Of all three variables, depressive symptoms seem to be the least affected by objective factors like sociodemographic variables or injury characteristics. Instead, our findings show them to be related to both perceived health and social support. Both of 
these variables have been suggested in other research to be susceptible to the negative halo effect of depression. Thus somaticization and negative perceptions commonly associated with depression may bias reports of health and social support in a negative direction.

Adjustment also, in our findings, appears unrelated to objective indicators like age and severity of disability, but is closely tied to health and support. Changes in health may require on-going adjustments, supporting Krause's contention that adjustment is not a finite process of approximately two years' duration, but a life-long process. The negative relationship of adjustment with instrumental support is interesting, in that it suggests that the more one is obliged to depend on others, the more one is inclined to harbour negative attributions about the disability. This finding is underscored by anecdotal remarks by participants about the importance placed on independence, and the drastic consequences that are expected to accompany even small losses in independence. Perhaps instrumental support acts as a constant reminder of the presence and impact of the disability.

Life satisfaction, on the other hand, is shown in our results and those of other researchers to be significantly influenced by tangible objective factors, like finances, as well as by perceptions of health and social support. Thus life satisfaction seems to offer an overall assessment of one's quality of life, including those features affected by the disability and those common to members of the general population.

It is also interesting to note the extremely high proportion of variance explained by the model for life satisfaction. Although one is initially skeptical of a model with this predictive ability, further consideration of the variables included reveals their pervasive natures. These three variables, finances, health and support, are potentially related to many other variables important to quality of life, like housing, recreation and employment, as well as pyschological variables like self esteem.

\section{Acknowledgements}

The authors gratefully acknowledge the financial support of the Ontario Lottery Grants Program, a program on the Ontario Ministry of Community and Social Services, administered by the Ontario Mental Health Foundation. The study was conducted with the support of Lyndhurst Spinal Cord Centre, Toronto, Canada.

\section{References}

1 Trieschmann R (1987) Aging With a Disability. Demos Publications, New York.

2 Burns TJ, Batavia AI, Smith QW, DeJong G (1990) Primary health care needs of persons with physical disabilities: What are the resource and service priorities? Arch Phys Med Rehabil 71: 138-43.

3 Dean A, Kolody B, Wood P (1990) Effects of social support from various sources on depression in elderly persons. J Health Soc Behav 31: 148-161.

4 Oxman TE, Berkman LF, Kasl S, Freeman DH, Barrett J (1992) Social support and depressive symptoms in the elderly. Am J Epidemiol 135: 356-68.

5 Fitzpatrick R, Newman S, Archer R, Shipley M (1991) Social support, disability and depression: A longitudinal study of rheumatoid arthritis. Soc Sci Med 33: 605-611.

6 Wineman NM (1990) Adaptation to multiple sclerosis: The role of social support, functional disability and perceived uncertainty. Nurs Res 39: 294-299.

7 Cushman LA, Haslett J (1992) Spinal cord injury: Ten and fifteen years after. Paraplegia 30: 690-696.

8 Siosteen M, Lundqvist C, Blomstrand C, Sullivan L, Sullivan M (1990) The quality of life of three functional spinal cord injury subgroups in a Swedish community. Paraplegia 28: 476-488.

9 Whiteneck G, Charlifue S, Frankel HL, Fraser MH, Gardner BP, Gerhart KA et al (1992) Mortality, morbidity and psychosocial outcomes of persons with spinal cord injury more than twenty years ago. Paraplegia 30: 617-30.

10 Eisenberg MG, Saltz CC (1991) Quality of life among spinal cord injured persons: Long-term rehabilitation outcomes. Paraplegia 29: 514-520.

11 Gerhart KA (1993) Personal perspectives. In: Whiteneck GG, Charlifue SW, Gerhart K et al, editors. Aging with Spinal Cord Injury. Demos Publications, New York.

12 Krause JS (1992) Longitudinal changes in adjustment after spinal cord injury: A fifteen year study. Arch Phys Med Rehabil 73: 564-568. 
13 Krause JS, Crewe NM (1991) Chronological age, time since injury and time of measurement: Effects of adjustment after spinal cord injury. Arch Phys Med Rehabil 72: 91-100.

14 Penning MJ (1990) Receipt of assistance by elderly people: Heirarchical selection and task specificity. Gerontologist 31: 220-227.

15 Grant I, Patterson TL, Yager J (1988) Social support in relation to physical health and symptoms of depression in the elderly. Am J Psychiatry 145: 1254-58.

16 Schulz R, Decker S (1985) Long-term adjustment to physical disability: The role of social support, perceived control, and self-blame. J Pers Soc Psychol 48: 1162-1172.

17 Brillhart B (1988) Family support for the disabled. Rehabil Nurs 13: 316-319.

18 Radloff LS (1977) The CES-D Scale: A self-report depression scale for research in the general population. Appl Psychol Measure 1: 385-401.

19 McColl MA, Skinner HA (in press) Measuring inter- and intra-personal resources for community living with a disability. Disabil Rehabil.

20 Noh S, Posthuma B (1990) Physical disability and depression: A methodological consideration. Can J Occup Ther 87: 9-15.

21 Christensen AJ, Turner CW, Slaughter OR, Holman JM (1989) Perceived family support as a moderator of well-being in end-stage renal disease. J Behav Med 12: 249-265.

22 Michalos A (1980) Satisfaction and happiness. Soc Indicators Res 8: 385-422.

23 Michalos A (1985) Multiple discrepancies theory. Soc Indicators Res 16: 347-413.

24 Bergner M, Bobbitt RA, Kressel S, Pollard WE, Gilson BS, Morris JR (1976) The Sickness Impact Profile: Conceptual formulation and methodology for the development of a health status measure. Int $J$ Health Serv 6: 393-415.

25 Bergner M, Bobbitt RA, Carter WB, Gilson BS (1981) The Sickness Impact Profile: Development and final revision of a health status measure. Med Care 19: 787-805.

26 Augustinsson LE, Sullivan L, Sullivan M (1986) Physical, psychological, and social function in chronic pain patients after epidural spinal electrical stimulation. Spine 11; 111-119.

27 Deyo RA, Diehl AK (1983) Measuring physical and psychosocial function in patients with low-back pain. Spine 8: 635-642.

28 Lundqvist C, Siösteen A, Blomstrand C, Lind B, Sullivan M (1991) Spinal cord injuries: Clinical, functional, and emotional status. Spine 16: 78-83.

29 Feather NT (1989) Financial Stress Scale. In: Feather NT, editor. The Psychological Impact of Unemployment. Springer-Verlag, New York.

30 Keith RA, Granger CV, Hamilton BB, Sherwin FS (1987) The Functional Independence Measure: A new tool for rehabilitation. In: Eisenberg MD, Grzesiak RC, editors. Advances in Clinical Rehabilitation. Springer, New York.

31 Chappell N, Strain L, Badger M (1988) Self-care in health and illness. Compr Gerontology 2: 92-101.

32 Cohen S, Mermelstein R, Kamarck T, Hoberman HM (1985) Measuring the functional components of social support. In: Sarason IG, Sarason BR, editors. Social Support: Theory, Research and Applications. Martinus Nijhoff, Boston.

33 McColl MA, Skinner HA (1988) Concepts and measurement of social support in a rehabilitation setting. Can J Rehabil 2: 93-107.

34 Friedland J, McColl MA (1992) Social support intervention after stroke: Results of a randomized trial. Arch Phys Med Rehabil 73: 573-81. 